\section{(O) OPEN ACCESS}

\title{
Objective measurement of compliance during oral appliance therapy for sleep-disordered breathing
}

\author{
Olivier M Vanderveken, ${ }^{1,5,6}$ Marijke Dieltjens, ${ }^{2,6}$ Kristien Wouters, $^{3}$ \\ Wilfried A De Backer, 4,5,6 Paul H Van de Heyning, ${ }^{1,5,6}$ Marc J Braem ${ }^{2,6}$
}

\begin{abstract}
- Additional data are published online only. To view these files please visit the journal online (http://dx.doi. org/10.1136/thoraxinl-2012 201900)
\end{abstract}

${ }^{1}$ Department of Otolaryngology and Head and Neck Surgery, Antwerp University Hospital, Antwerp, Belgium

${ }^{2}$ Department of Special Care Dentistry, Antwerp University Hospital, Antwerp, Belgium ${ }^{3}$ Department of Scientific Coordination and Biostatistics, Antwerp University Hospital,

Antwerp, Belgium

${ }^{4}$ Department of Pneumology, Antwerp University Hospital, Edegem, Antwerp, Belgium ${ }^{5}$ Multidisciplinary Sleep Disorders Unit, Antwerp University Hospital, Edegem, Antwerp, Belgium

${ }^{6}$ Faculty of Medicine and Health Sciences, University of Antwerp, Antwerp, Belgium

\section{Correspondence to}

Professor Dr Olivier M

Vanderveken, Department of Otolaryngology and Head and Neck Surgery, Antwerp University Hospital,

Wirrijkstraat 10, Edegem B-2650, Antwerp, Belgium; olivier.vanderveken@uza.be

Received 12 March 2012 Revised 13 August 2012 Accepted 24 August 2012 Published Online First 19 September 2012

\footnotetext{
To cite: Vanderveken $\mathrm{OM}$, Dieltjens $\mathrm{M}$, Wouters $\mathrm{K}$, et al. Thorax 2013, 68 91-96
}

\begin{abstract}
Background Oral appliance (OA) therapy is increasingly prescribed as a non-continuous positive airway pressure treatment modality for sleep-disordered breathing (SDB). Although OA therapy is reported to be efficacious for the treatment of SDB, data on compliance remain limited to self-report.

Methods In this 3-month prospective clinical trial, the main outcome was to assess the safety and feasibility of an objective measurement of compliance during $\mathrm{OA}$ therapy using an embedded microsensor thermometer with on-chip integrated readout electronics in 51 consecutive patients with an established diagnosis of SDB (AHI 18.0 $\pm 11.9 / \mathrm{h}$; age $47 \pm 10 \mathrm{y}$; BMI $26.6 \pm 4.0 \mathrm{~kg} / \mathrm{m}^{2}$; men/women: $\left.31 / 20\right)$. Patients were unaware of the purpose of the study.

Results No microsensor-related adverse events were recorded. In addition, no problems were encountered during the readout of the compliance data. Out of 51 microsensors, one had a technical defect and was lost to follow-up. In this study, the overall objective mean rate of $\mathrm{OA}$ use was $6.6 \pm 1.3 \mathrm{~h}$ per day with a regular $\mathrm{OA}$ users' rate of $82 \%$ at the 3-month follow-up. Statistical analysis revealed no significant differences between

\section{Key messages}

What is the key question?

- To assess the safety and feasibility of the objective measurement of compliance during oral appliance (OA) therapy for sleep-disordered breathing (SDB) using a microsensor thermometer embedded in the OA.

What is the bottom line?

- Although $\mathrm{OA}$ therapy is reported to be efficacious for the treatment of SDB, data on compliance remain limited to self-report.

\section{Why read on?}

- The objective measurement of OA compliance allows for the calculation of the mean disease alleviation, defined as a combined function of efficacy and compliance, being a measure of the overall therapeutic effectiveness, and will become imperative in the evaluation of $O A$ therapy success rates in the treatment of SDB.
\end{abstract} objective and self-reported OA compliance data in this study.

Measurement of the objective OA compliance allowed us to calculate the mean disease alleviation (MDA) as the product of objective compliance and therapeutic efficacy. MDA serves as a measure of the overall therapeutic effectiveness, and turned out to be $51.1 \%$. Conclusions The results illustrate the safety and feasibility of objective measurement of OA compliance. The objective measurement of OA compliance allows for calculation of the MDA.

\section{INTRODUCTION}

The prevalence of sleep-disordered breathing (SDB) is remarkably high among middle-aged adults, with estimates reaching $9 \%$ for women and $24 \%$ for men. ${ }^{1}$ SDB in adults spans a wide pathophysiological continuum of severity, from snoring over obstructive sleep apnoea (OSA) to obesity hypoventilation syndrome. ${ }^{2}$ Epidemiological studies provide clear evidence that SDB is a strong and independent risk factor for hypertension with consequent cerebro- and cardiovascular morbidity and high mortality. $^{3-5}$ As a result, SDB has major socioeconomic consequences. ${ }^{6}$

OSA is characterised by repetitive pharyngeal collapse (apnoea) or upper airway narrowing (hypopnoea) during sleep, leading to hypoxaemia and hypercapnia, and causing sleep fragmentation that in turn leads to daytime sleepiness and increased risk of motor vehicle and occupational accidents. $^{7-9}$ OSA is defined as the occurrence of more than five apnoeas and hypopnoeas per hour of sleep, expressed as the apnoea/hypopnoea index, or apnoea/hypopnoea index (AHI). The American Academy of Sleep Medicine (AASM) considers an AHI of between five and 15 to be mild OSA, between 15 and 30 to be moderate OSA, and $>30$ to be severe OSA. ${ }^{10}$

The gold standard for the treatment of OSA is continuous positive airway pressure (CPAP). ${ }^{11}{ }^{12}$ CPAP improves systemic hypertension, and it has been demonstrated that successful CPAP treatment prolongs survival..$^{5}$ Because of the high efficacy of CPAP, the therapeutic effectiveness of CPAP is potentially high. Its clinical effectiveness, however, is often limited by low patient acceptance, poor tolerance and a suboptimal CPAP compliance. ${ }^{13} 14$ Therefore, CPAP could result in a less favourable effectiveness than required. ${ }^{13}$ Accordingly, non-CPAP alternatives for the treatment of SDB have gained growing interest. ${ }^{13} 1516$ Oral appliance (OA) therapy is increasingly prescribed as a noninvasive first-line alternative to CPAP. ${ }^{15}$ Mandibular 
Figure 1 The microsensor

thermometer with on-chip integrated readout electronics used in this study (TheraMon, IFT Handels- und Entwicklungsgesellschaft $\mathrm{GmbH}$, Handelsagentur Gschladt, Hargelsberg, Austria) has a weight of $0.40 \pm 0.01 \mathrm{~g}$, a length of $13.0 \pm 0.1 \mathrm{~mm}$, a width of $9.0 \pm 0.1 \mathrm{~mm}$ and a height of 4.3 $\pm 0.1 \mathrm{~mm}$. The sampling interval of the temperature recording was programmed at one measurement per 15 min with a memory capacity of approximately 100 consecutive days.

advancement devices, which are worn intraorally at night to advance the mandible, are currently the most common class of OAs used to treat SDB. ${ }^{16-19}$ The efficacy of OA therapy has been demonstrated in randomised controlled clinical trials, and there is emerging evidence on its beneficial cardiovascular effects. ${ }^{15} 2021$ OA therapy is indicated in subjects who do not tolerate or comply with CPAP, and it may be a first-line treatment in snorers and patients with mild to moderate OSA. ${ }^{15} \mathrm{OA}$ therapy can also be considered as a temporary alternative for CPAP, or a rescue treatment after upper airway surgery failure. $^{7} 1522$

As a part of clinical routine, CPAP treatment incorporates a well established objective measurement of CPAP use. ${ }^{14} 2324$ To date, objective measurement of compliance during OA therapy for SDB remains restrained. ${ }^{15} 2526$

In this article, we describe the results of a 3-month prospective clinical trial assessing the safety and feasibility of the objective measurement of OA compliance using an embedded microsensor thermometer with on-chip integrated readout electronics.

\section{METHODS}

\section{Study design}

A structured written informed consent procedure was used. Subjects enrolled in the study were unaware that compliance with their OA was being measured objectively, and they were not paid for participation (for detailed information on the study protocol, see the online data supplement).

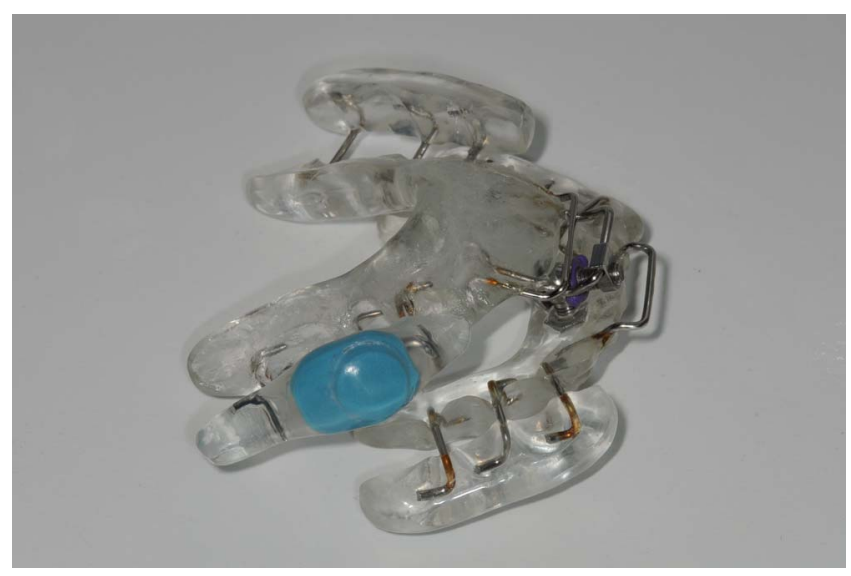

Figure 2 The microsensor is sealed into the upper right side of the custom-made titratable mandibular advancement device.

\section{Measurements}

Objective measurement of OA compliance was performed using an embedded microsensor thermometer (figure 1). Objective compliance measurement was based on the assumption that the OA therapy was being used when the temperature measured was higher than $35^{\circ} \mathrm{C}$. The microsensor was embedded in the upper right side of the $\mathrm{OA}$ (figure 2).

Additional details regarding the $\mathrm{OA}$ and the OA compliance monitor can be found in the online data supplement.

\section{Safety and feasibility endpoints}

The safety endpoint was the absence of any microsensor-related adverse effects (box 1). To determine these adverse effects, patients were interviewed during each follow-up evaluation about possible adverse effects, and an oral examination was performed. The OA was also examined by the dental sleep professional, including a detailed inspection of the area with the embedded microsensor. The feasibility endpoint was a successful readout of the compliance data from the microsensor.

\section{OA compliance measurements}

The objective OA compliance data were expressed as objective mean rate of OA use in number of hours of OA use per day, and as percentage of days of OA use per week. Patients were considered compliant when objective OA use $\geq 4 \mathrm{~h}$ per day. According to the literature, a set of two user patterns was identified (table 2). ${ }^{1424}$

Self-reported OA compliance and self-reported total sleep time (TST) were assessed using a diary filled out by the patient on each day of the 3-month follow-up period during the intervals between the follow-up visits.

Adjusted compliance will be calculated as the objective mean rate of OA use divided by TST.

\section{Polysomnographic outcome}

All patients underwent an attended, overnight level I polysomnography with OA 3 months after the start of OA therapy. Treatment response and treatment success were defined by a

Box 1 Microsensor-related adverse effects as defined for the purpose of this study

- The occurrence of oral burn injuries

- Other microsensor-related lesions to the oral mucosa

- Detachment of the microsensor from the oral appliance 
Table 1 The objective mean rate of OA use, expressed in hours per day, and the percentage of days of OA use per week for the separate months and consistent for the 3-month study period

\begin{tabular}{llll}
\hline & $\begin{array}{l}\text { objective mean rate } \\
\text { of OA use (h/day) }\end{array}$ & $\begin{array}{l}\text { Objective } \% \\
\text { days/week }\end{array}$ & $\mathbf{n}$ \\
\hline First month & $6.8 \pm 1.4$ & $93.3 \pm 11.3$ & 43 \\
Second month & $6.7 \pm 1.3$ & $92.5 \pm 11.2$ & 43 \\
Third month & $6.6 \pm 1.6$ & $91.8 \pm 14.5$ & 43 \\
Consistent over 3 months & $6.7 \pm 1.3$ & $91.9 \pm 10.8$ & 43 \\
\hline
\end{tabular}

Data are presented as mean $\pm \mathrm{SD}$.

$\mathrm{OA}$, oral appliance.

$\geq 50 \%$ reduction in $\mathrm{AHI}$ and an $\mathrm{AHI}<5 / \mathrm{h}$ sleep, respectively. Therapeutic OA efficacy was defined as baseline AHI minus AHI with OA, expressed in percentage.

\section{OA effectiveness}

According to the 'disease alleviation concept', ${ }^{13}$ objective measurement of OA compliance allows us to calculate the mean disease alleviation (MDA) (\%), as a measure of therapeutic OA effectiveness. MDA is given by the product of adjusted compliance with therapeutic OA efficacy, divided by 100 . The overall remaining $\mathrm{AHI}$ was calculated as the product of baseline $\mathrm{AHI}$ and (100 minus MDA)/100.

\section{Statistics}

Data were statistically analysed using SPSS (SPSS V.17.0, SPSS Inc, Chicago, Illinois, USA). The significance level was set at 0.05 . Quantitative variables were presented as mean \pm SD. Normality of distribution was assessed using the KolmogorovSmirnov test. OA treatment effects were analysed with a paired t-test if the data were normally distributed, and with the Wilcoxon signed-rank test if they were not. To compare the data on self-reported OA compliance with the objective OA use a Wilcoxon signed-rank test was performed.

\section{RESULTS}

A group of 51 patients with an established diagnosis of SDB based on an attended, overnight level I polysomnography (age $47 \pm 10$ y; BMI $26.6 \pm 4.0 \mathrm{~kg} / \mathrm{m}^{2}$; men/women: 31/20; AHI 18.0 $\pm 11.9 / \mathrm{h}$ sleep; Epworth sleepiness scale $10.8 \pm 4.7$ ) who were undergoing OA therapy were included ${ }^{10} 1^{17} \quad 27-29$ (for details, see the online data supplement).

Table 2 A set of two user patterns* was identified and calculated: percentages of regular and frequent users over the separate months and consistent for the 3-month study period

\begin{tabular}{lllll}
\hline & Regular users & $\%$ & Frequent users & $\%$ \\
\hline First month & $45 / 50$ & 90 & $45 / 50$ & 90 \\
Second month & $41 / 45$ & 91 & $40 / 45$ & 89 \\
Third month & $36 / 43$ & 84 & $36 / 43$ & 84 \\
Consistent over 3 months & $36 / 43$ & 84 & $34 / 43$ & 79 \\
\hline
\end{tabular}

*Patients were classified as 'regular users' if they completed at least $4 \mathrm{~h}$ of active oral appliance (OA) treatment on more than $70 \%$ of the days of the week, as defined by Kribbs et al. ${ }^{14}$ Patients were classified as 'frequent users' when they met the more restrictive criteria introduced by Pepin et al: mean OA use of more than 5 days per week and more than $4 \mathrm{~h}$ per day. ${ }^{24}$
Table 3 Median values and first and third quartiles (Ql; Q3) of objective and self-reported mean rate of OA use data as assessed during the intervals between the follow-up visits

\begin{tabular}{lllll}
\hline & $\begin{array}{l}\text { Median objective } \\
\text { compliance (h/day) }\end{array}$ & $\begin{array}{l}\text { Median self-reported } \\
\text { compliance (h/day) }\end{array}$ & p Value & N \\
\hline $\begin{array}{l}\text { First month } \\
\text { Second+third }\end{array}$ & $7.24(6.72 ; 7.87)$ & $7.34(6.06 ; 7.83)$ & 0.804 & 31 \\
month & $7.13(6.69 ; 7.66)$ & $7.21(6.69 ; 7.76)$ & 0.576 & 31 \\
\hline OA, oral appliance. & & & & \\
\hline
\end{tabular}

\section{Safety and feasibility endpoints}

Based on history and clinical examination at both the 1-month and the 3-month follow-up visit, no microsensor-related adverse events (box 1) were recorded. Detailed inspection of the OAs during any follow-up evaluation did not reveal any abnormalities or changes to the area of the OA where the microsensor was embedded. No detachments have occurred.

From a feasibility perspective, no problems were encountered during the readout of the compliance data during any of the follow-up evaluations. One out of 51 microsensors had a technical defect and was lost to follow-up.

\section{OA compliance measurements}

No patients discontinued OA therapy during the 3-month follow-up period. The readout of the OA-compliance monitor data was performed at a 1 -month (32 \pm 3 days) and a 3 -month (95 \pm 8 days) interval. In four patients, the final readout date exceeded the 100-day storage period of the microsensor, and in four other patients compliance data were read out for the first and second months, but not obtained for the total 3-month period. Therefore, for the complete follow-up period, compliance data are available for 43 out of 51 patients (table 1). Over the 3 months, the objective OA use was consistently $6.7 \pm 1.3 \mathrm{~h}$ per day with OA being used on $91.9 \pm 10.8 \%$ of days per week $(n=43)$ (table 1). Forty-two out of 45 patients $(93 \%)$ had an objective mean rate of OA use that exceeded $4 \mathrm{~h}$ per day and were considered compliant. Overall, the self-reported TST for the whole follow-up period was $7.5 \pm 0.9 \mathrm{~h} /$ day. The percentages of regular and frequent users are shown in table 2 . The percentage of regular users was consistently $84 \%$ over the 3 months $(n=43)$.

Table 4 Data at baseline compared with data after OA use

\begin{tabular}{lllc}
\hline Parameter & Baseline (mean \pm SD) & With OA (mean \pm SD) & p Value \\
\hline AHI (events/h) & $18.4 \pm 11.5$ & $7.0 \pm 6.5$ & $<0.001$ \\
ODI (events/h) & $6.2 \pm 7.5$ & $2.8 \pm 3.0$ & $<0.01$ \\
Mean sat (\%) & $94.7 \pm 1.4$ & $95.0 \pm 1.3$ & 0.254 \\
Min sat (\%) & $85.1 \pm 6.8$ & $85.7 \pm 6.6$ & 0.658 \\
TST (uu:mm:Ss) & $06: 02: 15 \pm 1: 29: 52$ & $06: 16: 22 \pm 1: 31: 40$ & 0.600 \\
$\%$ S1 in TST & $8.0 \pm 4.9$ & $5.0 \pm 3.5$ & 0.001 \\
$\%$ S2 in TST & $49.8 \pm 10.3$ & $52.1 \pm 11.5$ & 0.287 \\
$\%$ S3 in TST & $21.8 \pm 8.9$ & $22.1 \pm 10.6$ & 0.865 \\
$\%$ REM in TST & $20.2 \pm 6.5$ & $20.8 \pm 6.2$ & 0.607 \\
Arousal index & $15.5 \pm 14.0$ & $7.6 \pm 3.4$ & 0.004 \\
(events/h) & & & $<0.001$ \\
ESS (/24) & $10.8 \pm 4.7$ & $7.8 \pm 4.8$ & $<0.001$ \\
Snoring index (0-10) & $6.5 \pm 2.6$ & $2.4 \pm 2.3$ & 0.767 \\
BMI (kg/m ${ }^{2}$ ) & $26.6 \pm 4.2$ & $26.7 \pm 4.1$ & \\
\hline
\end{tabular}

ESS, Epworth sleepiness scale; OA, oral appliance; ODI, Oxygen Desaturation Index; REM, Rapid Eye Movement; TST, total sleep time; AHI, apnoea/hypopnoea index. 
Statistical analysis revealed no significant differences between objective and self-reported OA compliance data in this study (table 3).

\section{Polysomnographic outcomes}

For 43 of the 51 patients, polysomnography with OA was obtained (table 4). Overall, treatment response and treatment success occurred in $62 \%$ and $50 \%$ of patients, respectively. Mean AHI decreased from $18.4 \pm 11.5$ at baseline to $7.0 \pm 6.5 / \mathrm{h}$ sleep with OA $(\mathrm{p}<0.001)$, leading to an OA efficacy of 56.0 $\pm 38.2 \%(\mathrm{n}=43)$.

\section{OA effectiveness}

In figure 3 , the individual OA efficacy percentages are plotted against the individual OA compliance data expressed in percentage of days of OA use per week. Over the 3-month follow-up period, adjusted compliance (objective OA use/TST) was 91.2 $\pm 10.1 \%$ (range $67.8 \%-100 \%$ ). MDA was $51.1 \%$ and was calculated by the product of OA efficacy and adjusted compliance divided by 100 (see figure 4). The overall remaining AHI was $7.8 \pm 5.4 / \mathrm{h}$ sleep, calculated as the product of baseline AHI and (100 minus MDA)/100.

\section{DISCUSSION}

Objective measurements of CPAP compliance with a built-in measurement of actual compliance have become a routine part of daily clinical practice. ${ }^{12}$ By contrast, OA therapy lacks the possibility to record objective daily use, as compliance data remain limited to self-report. ${ }^{15}$ In the 2005 AASM practice parameter report, Kushida et al claim that the development of similar capabilities to monitor OA compliance in an objective fashion are required for both research and clinical purposes. ${ }^{15}$ As in the early years of $\mathrm{CPAP}^{23}$ there is a strong interest in this objective compliance measurement. The present study reports in-depth on the safety and feasibility of objective compliance monitoring during OA therapy. This objective measurement of OA compliance allowed us to establish the MDA as a measure of therapeutic effectiveness.

In our prospective study, no adverse effects were noted related to the compliance monitoring using an active microsensor thermometer (box 1), illustrating the safety of this device.

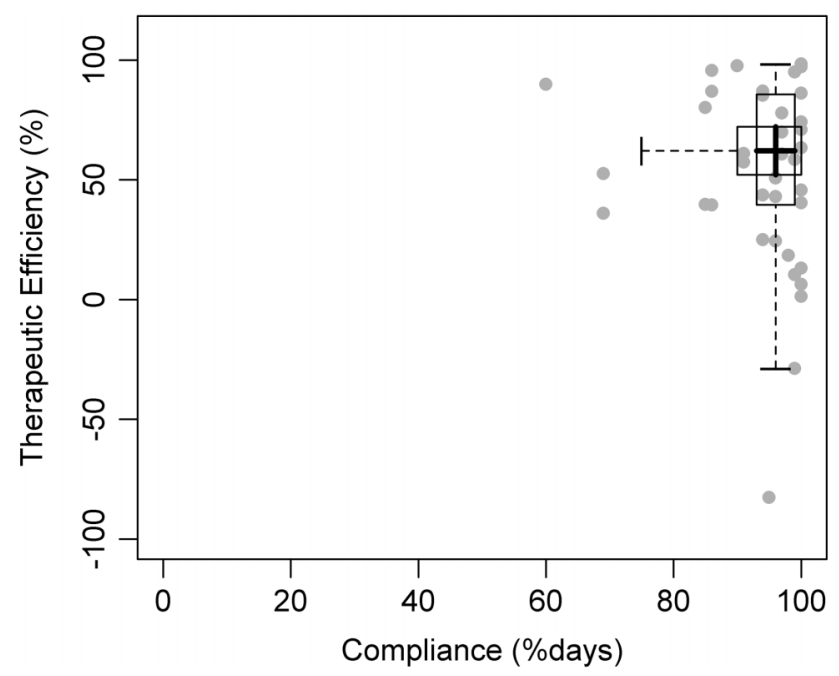

Figure 3 The individual oral appliance (OA) efficacy percentages plotted against the individual $O A$ compliance data, expressed in percentage of days of OA use per week.
Only 1 out of 51 microsensors had a technical defect. During 3 months of OA therapy, it was feasible to obtain data on objectively measured compliance (table 1). Objective OA use was high, with patients using the therapy on average $6.7 \pm 1.3 \mathrm{~h}$ per day over the 3-month follow-up period consistently, while the 3-month regular users' rate was $84 \%$ (table 2). These high OA use rates clearly illustrate that compliance probably is not a major limitation in the use of OAs for the treatment of SDB. ${ }^{31}$

Two previous papers have been published in the literature that are relevant to this study. Lowe et al were the first to report on the direct intraoral recording of OA compliance during sleep over a 2 -week time span in eight OSA patients. ${ }^{25}$ Their compliance monitor was composed of a ceramic thick-film hybrid with a memory system and a temperature sensor. ${ }^{25}$ Objective OA use values of $6.9 \mathrm{~h} /$ day were recorded, and thus, the study showed comparable high compliance data during OA therapy. Nevertheless, several problems were reported with the compliance monitors that were used, including heat intolerance of the electronic components and high energy consumption over longer sampling periods. ${ }^{25}$

Inoko et al reported on the assessment of the cytotoxicity of a temperature data logger in six OSA patients during 1 month. ${ }^{26}$ In this study, the surface of the temperature data logger was coated with a temporary sealing material to prevent contact with oral mucosa. ${ }^{26}$ Another limitation of this specific study was the dimensions of the temperature data logger, which had a diameter of $17.4 \mathrm{~mm}$, a thickness of $5.9 \mathrm{~mm}$, and a weight of about $3.3 \mathrm{~g}^{26}$ as compared with the microsensor thermometer used in our study having a weight of only $0.4 \mathrm{~g}$ and a length, width and height of 13,9 and $4.3 \mathrm{~mm}$, respectively (figure 1). It is possible that the technical problems limiting the use of compliance monitors in both these studies ${ }^{25} 26$ impeded the availability of objective measurement of OA compliance in the field of sleep medicine to date.

To the authors' best knowledge, our study is the first to report the safety and feasibility of objective compliance monitoring during OA therapy in a larger group of SDB patients over a 3 -month period. Another important result of this study is the establishment of the MDA calculation. The availability of an objective measurement of compliance allowed us to introduce

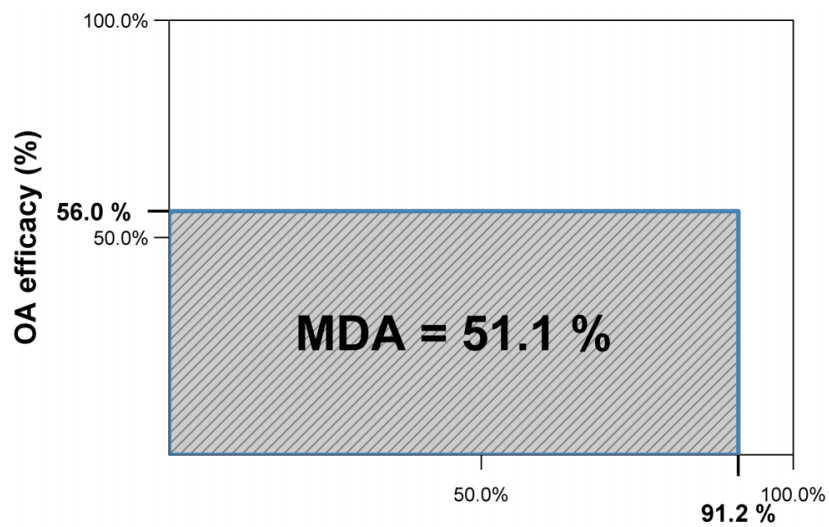

Adjusted OA compliance (\%)

Figure 4 Mean disease alleviation (MDA) is equal to the surface area of the rectangle for which the length is given by the adjusted compliance (objective oral appliance (OA) use/total sleep time), and the height is given by the therapeutic efficacy ( $\mathrm{AHI}$ baseline minus $\mathrm{AHI}$ with $\mathrm{OA}$ applied, expressed in percentage). MDA provides a measure of overall therapeutic effectiveness. 
this calculation into the field of OA therapy as a measure of the overall therapeutic effectiveness, given by the product of adjusted compliance and OA efficacy, divided by 100 and expressed in percentage. MDA was $51.1 \%$ in the reported study (figure 4). These figures on therapeutic effectiveness support the hypothesis that higher compliance with mandibular advancement device type of OA therapy translates into a similar adjusted effectiveness as compared with CPAP ${ }^{32}$ Although mandibular advancement device treatment is inferior to CPAP in reducing the AHI, its MDA values might be comparable with those of CPAP because of the higher compliance with OA therapy. $^{32}$

Taking into account the fact that even the most effective medical device is only effective when it is used, the authors believe that MDA calculation is of high interest because there is a clear need for well-defined criteria to compare the effects of CPAP therapy and non-CPAP treatment options. ${ }^{33}$ In the past, the absence of a safe and reliable method for objective measurement of OA compliance prevented calculation of MDA for OA therapy. The results of this study provide evidence to overcome this limitation. With CPAP, about 50\% adjusted effectiveness is observed when accounting for sleep time, its actual effect and use. $^{13} 33$ In a recent paper, Ravesloot et al provided evidence that the effectiveness of suboptimal use of CPAP therapy could indeed be comparable with the subtherapeutic effect of a given surgical treatment. ${ }^{33}$ In our study, the overall therapeutic effectiveness during OA therapy was $51.1 \%$, combining a high compliance with a suboptimal efficacy (figure 4). Moreover, in the reported study, no patients discontinued OA therapy during the 3-month follow-up period, whereas approximately 20\%-40\% of patients will discontinue CPAP after 3 months. ${ }^{34}$

We believe the use of a titratable custom-made mandibular advancement device is another strength of our study, as this type of OA is currently recommended. ${ }^{16} 17 \quad 30 \quad 32 \quad 35$ It has been reported that both comfort and efficacy might turn out to be higher with such titratable custom-made appliances, presumably leading to an improvement in compliance and effectiveness. ${ }^{35}$

The present study has its limitations and shortcomings. First, only a relatively small number of patients were included, and the follow-up period was relatively short. Further prospective evaluation with a larger number of patients and longer follow-up periods are required to confirm these first results. The second limitation was that the reported study, as a safety and feasibility trial, had no control group. However, we believe this bias was minimal because patients were unaware that their OA compliance was being measured objectively. As this was a clinical research trial, differences may occur in a daily clinical practice with a stricter follow-up schedule. There is a lower tendency for drop-out in a clinical study as compared with daily clinical practice. Another bias might have been introduced by the fact that the study group mainly consisted of patients with mild to moderate OSA. It is well known that mandibular advancement devices are more successful in the treatment of mild to moderate OSA than severe OSA. ${ }^{16}{ }^{25}$ Moreover, patients suitable for and willing to start OA therapy were preselected after clinical dental and ENT examination.

Despite its limitations, we expect that this study will be able to serve as a key step forward in the development of future guidelines concerning both clinical practice and research projects. The microsensor thermometer used in this study (figure 1) has proven to be reliable within the 3-month follow-up period. Extended follow-up is needed to provide additional information on the long-term safety and feasibility of this chip, including the life time and battery life of the chip.
The authors believe that the results of this study have important implications for future clinical trials evaluating OA therapies for patients with SDB as an objective measurement of OA use, and that OA compliance will become imperative in the evaluation of OA therapy success rates. In addition, as with CPAP treatment, a compliance-based coverage of OA therapy might be adopted by healthcare programs and insurance companies. ${ }^{36}$

\section{CONCLUSIONS}

The removable nature of an OA warrants objective assessment of its effective use and compliance in the treatment of SDB. Although there is a strong interest in this type of assessment, objective measurement has been restrained to date. Our findings suggest that objective measurement of $\mathrm{OA}$ compliance during SDB treatment is safe and feasible.

Consistently over the 3-month follow-up period, the rate of regular OA users was $82 \%$ with an average objective OA use of $6.7 \pm 1.3 \mathrm{~h}$ per day. Compared with CPAP compliance that is often poor, the high levels of compliance during OA therapy in this study are favourable. This relatively high compliance will favourably influence the MDA, defined as a combined function of efficacy and compliance, being a measure of the overall therapeutic effectiveness of this specific therapeutic option as compared with other treatment modalities for SDB. ${ }^{13}$ In the reported study, the MDA was calculated as $51.1 \%$, which is comparable with the 50\% adjusted CPAP effectiveness. ${ }^{13}$ These results fit the hypothesis that mandibular advancement device treatment, despite being inferior to CPAP in reducing the AHI, might translate into a similar adjusted AHI and effectiveness because of a higher compliance. ${ }^{32}$

Based on the results of this study, it is recommended that actual OA use should be objectively recorded in all SDB patients undergoing OA therapy, and that the use of an objective instrument to measure OA compliance should be implemented in future studies. Further prospective studies with larger numbers of patients and longer follow-up periods are required to confirm our first results and to assess the evolution of OA compliance patterns over time.

Acknowledgements The TheraMon microsensor thermometers and readout equipment used in this study were provided free of charge by IFT Handels- und Entwicklungsgesellschaft GmbH, Handelsagentur Gschladt, Hargelsberg, Austria. The TheraMon microsensor thermometers were sealed in the Respident Butterfly MRA oral appliances by the Respident dental laboratory, Schoten, Belgium, free of charge. We are grateful to both for their support. The supporting companies had no role in study design, data collection, data analysis, data interpretation or writing of the report.

Contributors OMV, MJB: Substantial contributions to conception and design; OMV, MD, MJB: acquisition of data; OMV, MD, KW, PHVDH, MJB: analysis and interpretation of data; OMV, MD: drafting the article; OMV, MD, KW, WADB, PHVDH, MJB: revising critically the article for important intellectual content; OMV, MD, KW, WADB, PHVDH, MJB: final approval of the version to be published.

\section{Competing interests None.}

Provenance and peer review Not commissioned; externally peer reviewed.

Open Access This is an Open Access article distributed in accordance with the Creative Commons Attribution Non Commercial (CC BY-NC 3.0) license, which permits others to distribute, remix, adapt, build upon this work non-commercially, and license their derivative works on different terms, provided the original work is properly cited and the use is non-commercial. See: http://creativecommons.org/ licenses/by-nc/3.0/

\section{REFERENCES}

1 Young T, Palta M, Dempsey J, et al. The occurrence of sleep-disordered breathing among middle-aged adults. N Engl J Med 1993;328:1230-5.

2 Piper AJ, Grunstein RR. Obesity hypoventilation syndrome: mechanisms and management. Am J Respir Crit Care Med 2011;183:292-8. 
3 Peppard PE, Young T, Palta M, et al. Prospective study of the association between sleep-disordered breathing and hypertension. N Engl J Med 2000;342:1378-84.

4 Yaggi HK, Concato J, Kernan WN, et al. Obstructive sleep apnea as a risk factor for stroke and death. N Engl J Med 2005;353:2034-41.

5 Robinson GV, Stradling JR, Davies RJ. Sleep . 6: obstructive sleep apnoea/ hypopnoea syndrome and hypertension. Thorax 2004;59:1089-94.

6 Jennum P, Kjellberg J. Health, social and economical consequences of sleep-disordered breathing: a controlled national study. Thorax 2011;66:560-6.

7 Malhotra A, White DP. Obstructive sleep apnoea. Lancet 2002;360:237-45.

8 Fogel RB, Malhotra A, White DP. Sleep. 2: pathophysiology of obstructive sleep apnoea/hypopnoea syndrome. Thorax 2004;59:159-63.

9 George CF. Sleep. 5: driving and automobile crashes in patients with obstructive sleep apnoea/hypopnoea syndrome. Thorax 2004;59:804-7.

10 The Report of an American Academy of Sleep Medicine Task Force. Sleep-related breathing disorders in adults: recommendations for syndrome definition and measurement techniques in clinical research. Sleep 1999;22:667-89.

11 Sullivan CE, Issa FG, Berthon-Jones M, et al. Reversal of obstructive sleep apnoea by continuous positive airway pressure applied through the nares. Lancet 1981;1:862-5.

12 Grunstein RR. Sleep-related breathing disorders. 5. Nasal continuous positive airway pressure treatment for obstructive sleep apnoea. Thorax 1995;50:1106-13.

13 Grote L, Hedner J, Grunstein R, et al. Therapy with nCPAP: incomplete elimination of sleep related breathing disorder. Eur Respir J 2000;16:921-7.

14 Kribbs NB, Pack Al, Kline LR, et al. Objective measurement of patterns of nasal CPAP use by patients with obstructive sleep apnea. Am Rev Respir Dis 1993;147:887-95.

15 Kushida CA, Morgenthaler TI, Littner MR, et al. Practice parameters for the treatment of snoring and obstructive sleep apnea with oral appliances: an update for 2005. Sleep 2006;29:240-3.

16 Marklund M, Verbraecken J, Randerath W. Non-CPAP therapies in obstructive sleep apnoea mandibular advancement device therapy. Eur Respir J 2012;39:1241-7.

17 Vanderveken OM, Devolder A, Marklund M, et al. Comparison of a custom-made and a thermoplastic oral appliance for the treatment of mild sleep apnea. Am J Respir Crit Care Med 2008;178:197-202.

18 Ryan CF, Love LL, Peat D, et al. Mandibular advancement oral appliance therapy for obstructive sleep apnoea: effect on awake calibre of the velopharynx. Thorax 1999;54:972-7.

19 Chan AS, Sutherland K, Schwab RJ, et al. The effect of mandibular advancement on upper airway structure in obstructive sleep apnoea. Thorax 2010;65:726-32.

20 Barnes M, McEvoy RD, Banks S, et al. Efficacy of positive airway pressure and oral appliance in mild to moderate obstructive sleep apnea. Am J Respir Crit Care Med 2004;170:656-64.
21 Gotsopoulos H, Kelly JJ, Cistulli PA. Oral appliance therapy reduces blood pressure in obstructive sleep apnea: a randomized, controlled trial. Sleep 2004;27:934-41.

22 Smith DM, Stradling JR. Can mandibular advancement devices be a satisfactory substitute for short term use in patients on nasal continuous positive airway pressure? Thorax 2002:57:305-8.

23 Krieger J, Kurtz D. Objective measurement of compliance with nasal CPAP treatment for obstructive sleep apnoea syndrome. Eur Respir J 1988;1:436-8.

24 Pepin JL, Krieger J, Rodenstein D, et al. Effective compliance during the first 3 months of continuous positive airway pressure. A European prospective study of 121 patients. Am J Respir Crit Care Med 1999;160:1124-9.

25 Lowe AA, Sjoholm TT, Ryan CF, et al. Treatment, airway and compliance effects of a titratable oral appliance. Sleep 2000;23(Suppl 4):S172-8.

26 Inoko Y, Yoshimura K, Kato C, et al. Efficacy and safety of temperature data loggers in measuring compliance with the use of oral appliances. Sleep Biol Rhythms 2009;7:188-92.

27 Kushida CA, Littner MR, Morgenthaler T, et al. Practice parameters for the indications for polysomnography and related procedures: an update for 2005. Sleep 2005;28:499-521.

28 Petit FX, Pepin JL, Bettega G, et al. Mandibular advancement devices: rate of contraindications in 100 consecutive obstructive sleep apnea patients. Am J Respir Crit Care Med 2002;166:274-8.

29 Dieltjens M, Vanderveken OM, Hamans E, et al. Treatment of obstructive sleep apnea using a custom-made titratable duobloc oral appliance: a prospective clinical study. Sleep Breath Published Online First; May 2012. doi:10.1007/ s11325-012-0721-3

30 Dieltjens $\mathrm{M}$, Vanderveken $\mathrm{OM}$, Van de Heyning PH, et al. Current opinions and clinical practices in the titration of oral appliances in the treatment of sleep-disordered breathing. Sleep Med Rev 2012;16:177-85.

31 Gagnadoux F, Fleury B, Vielle B, et al. Titrated mandibular advancement versus positive airway pressure for sleep apnoea. Eur Respir I 2009;34:914-20.

32 de Almeida FR. Complexity and efficacy of mandibular advancement splints: understanding their mode of action. J Clin Sleep Med 2011;7:447-8.

33 Ravesloot MJ, de Vries N. Reliable calculation of the efficacy of non-surgical and surgical treatment of obstructive sleep apnea revisited. Sleep 2011;34:105-10.

34 Weaver TE, Grunstein RR. Adherence to continuous positive airway pressure therapy: the challenge to effective treatment. Proc Am Thorac Soc 2008;5:173-8.

35 Lettieri CJ, Paolino N, Eliasson AH, et al. Comparison of adjustable and fixed oral appliances for the treatment of obstructive sleep apnea. J Clin Sleep Med 2011;7:439-45.

36 Brown LK. Adherence-based coverage of positive airway pressure treatment for sleep apnea: the 'brave new world' of cost-saving strategies. Curr Opin Pulm Med 2011;17:403-5 